\title{
Shielding design and radioprotection for Andromede and ThomX accelerators
}

\author{
Jean-Michel Horodynski ${ }^{1, *}$, and Sebastien Wurth ${ }^{2}$ \\ ${ }^{1}$ iRSD - ingénierie Radioprotection sûreté démantèlement, UPS3364, CNRS/INP, 91898 Orsay, France \\ ${ }^{2}$ IPNO - Institut de physique nucléaire d'Orsay, UMR8608, CNRS/IN2P3, Université Paris-Sud, 91898 Orsay, France
}

\begin{abstract}
The Institut de physique nucléaire - Institute of Nuclear Physics (IPN) and the Laboratoire de l'accélérateur linéaire - Laboratory of the linear accelerator (LAL) are about to build two accelerators at the University Paris-Sud, Orsay. Andromede is a new imaging mass spectrometry instrument for surface analysis: the electron positron emission microscope (EPEM) will analyse impacts on a surface made by nano-particles (Au404) in the $\mathrm{keV}$ to $\mathrm{MeV}$ range to study ion-surface interactions. ThomX is a compact X-ray source (energy up to $90 \mathrm{keV}$ - flux up to $10^{13}$ photons. $\mathrm{s}^{-1}$ ) that will produce X-rays using Compton backscattering effect between an electron beam and a laser. In order to use these machines in the same area, hutches are designed to comply with French regulations for radiation protection. This paper presents the methods used to design the hutches, complying with safety objectives, technical issues and budget.
\end{abstract}

\section{Introduction}

Andromede [1] and ThomX [2] are new accelerators conceived by two French research laboratories, respectively IPN (Institut de physique nucléaire) and LAL (Laboratoire de l'accélérateur linéaure). Based at the Universite Paris-Sud at Orsay, these two facilities are going to be settled in the same building called "Igloo", which previously sheltered the synchrotron storage ring DCI of LURE, dismantled three years ago [3].

\subsection{Purpose of IGLEX}

IGLEX is a multidisciplinary center for technologies and applied sciences. The main goal is the research and development on accelerators and their use in various application fields: bio-chemical, astrophysics, materials science, medical imagery \& therapy and cultural heritage.

Andromede is a Secondary Ion Mass Spectrometry (SIMS) for nano-domains and nano-objects. A Van der Graaf generator will accelerate nano-particles of $\mathrm{Au}$ (Au4004+ up to $\mathrm{Au} 10000 \mathrm{n}+$ ) and $\mathrm{C}_{60}{ }^{\mathrm{n}+}$ fullerenes between 1 to $4 \mathrm{MeV}$. Ions will be produced by two sources, a Liquid Metal Ion Source (LIMS) as a NanoParticle Ion Source (NIPS) provided by Orsay Physics and an Electron Cyclotron Resonance source (ECR) for multi-charged molecular ions, provided by Pantecknik.

ThomX is a source of X-rays of high flux and energy, produced by backscattering Compton interaction. The linear accelerator will produce a $70 \mathrm{MeV}$ electron beam which will be injected in the compact storage ring (greater diagonal of about $7 \mathrm{~m}$ length). The X-rays will be produced with the interaction between electrons and photons coming from an amplified laser within a FabryPerot cavity [4]. The purpose of ThomX is to demonstrate that historical heritage study and Xray imaging can be affordable for a museum, or a large hospital, due to the compactness of the installation.

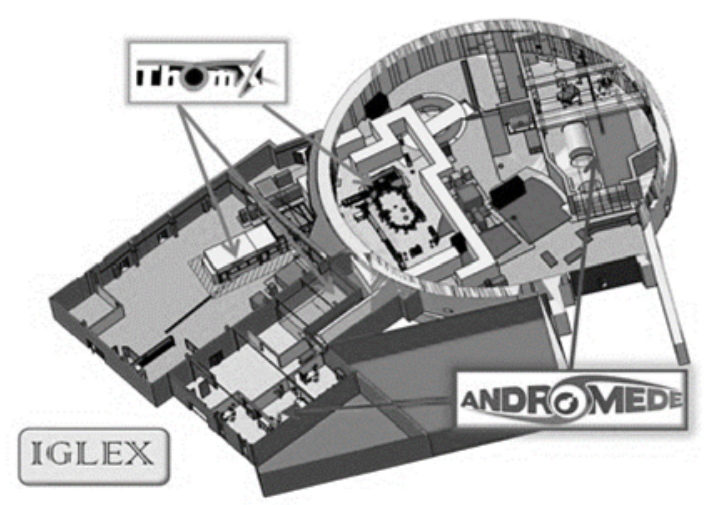

Fig. 1 IGLEX with the two accelerators, Andromede (IPN) and ThomX (LAL).

\subsection{Limitations - specificities for the radiation protection}

iRSD (ingénierie Radioprotection Sûreté Démantèlement - engineering in Radiation protection, Safety and Dismantling) and IPN radiation safety teams, due to their experience and expertise, are in charge of the studies leading to a high level of performance in operational and occupational safety, including radiation protection. On 
this purpose, national regulations and the French standard NF M 62-105 [5] for industrial accelerators have to be implemented.

As shown in fig. 2, the two accelerators will be placed in the same area but each one will be operated independently. Therefore, one bunker has to be built for each accelerator.

In the same time, workers could be present in one hutch or in the area between the two bunkers, called "circulation area" while one or both accelerators will work. In order to reduce radiation exposure while complying with technical and economic limitations, both teams proceed with a process of radiation protection optimization.

In particular maximum load of the ground limits the weight of the radiological protection used to design the bunkers. So, following the French regulations, circulation area will be defined as a "Zone Surveillée" or "Monitored Area", considering that the highest radiation level allowed is $7,5 \mu \mathrm{Sv}$ per hour for a worker. To avoid unexpected interferences, radiation levels around each shielding hutch are limited to $3 \mu \mathrm{Sv} \cdot \mathrm{h}^{-1}$ at the most.

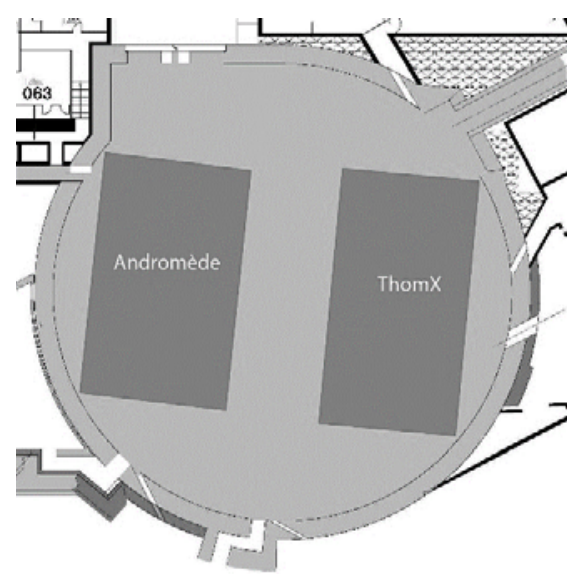

Fig. 2. Radiation protection zoning in the "Igloo" during the exploitation of Andromede and ThomX. In gray, the circulation area classified as "Zone Surveillée" (Monitored Area). In dark grey, the two hutches classified as "Zone Interdite" (Prohibited Area).

Access control, radiation monitoring system, command control and safety need to be installed considering the bunkers and specifications from AFNOR standard [5]. Interaction between components from the two machines had been designed to protect workers and to minimize operational constraints (Fig. 3). For example, radiation monitoring system interlocked with both accelerators stopped them if the level of radiation above the limit is detected. In the same time, access in hutches will be independent, except for the door leading to the circulation area (if the door stays opened during a time superior to a defined limit, both accelerators will stop).

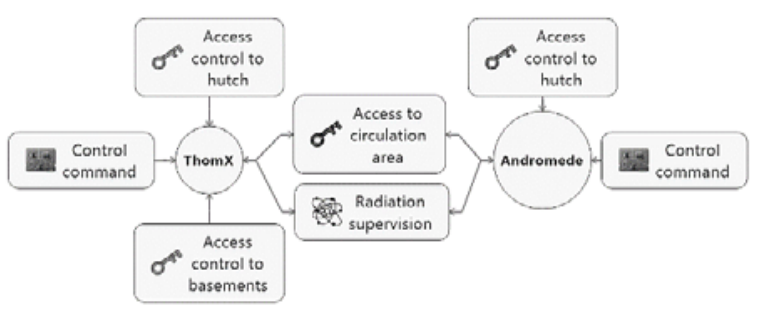

Fig. 3 : Simplified diagram about interlocks between safety components and accelerators in IGLEX plant.

Both project-teams need a strong coordination for risks assessment and operational safety of two plants in one building. LAL, supported by iRSD, and IPN work together to conduct radiation protection and operational safety studies. At the end, for the first time, both laboratories will provide the French nuclear authority, ASN (Autorité de sûreté nucléaire), two applications files with some common parts: operational and occupational safety, health and safety, radiation protection (Fig. 4).

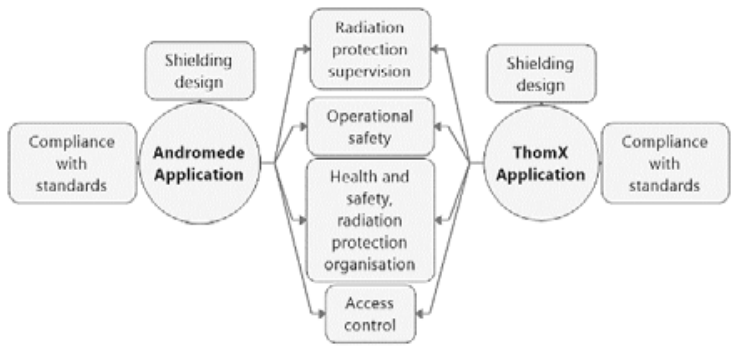

Fig. 4. Common and specific parts of the two application files in order to obtain the license to use the two accelerators.

The health and safety organization needs to be reliable and efficient. In this way, an agreement between three different partners, LAL, IPN and iRSD, is currently drafted to define responsibilities and operational scope of each laboratory.

\section{Method used for shielding designs}

Monte-Carlo codes of transport and interaction of particles are the most powerful tools to assess ionising radiation risks for accelerators. From shielding design to radiation protection and activation assessment, their capabilities increased over the past years. Choosing which code to use lies on multiple criteria, specifically: the kind of study to do, the results of benchmarking and comparisons tests, the regular updates of the code, the interactions between users and the accessibility of the code.

\subsection{FLUKA as a multi-purpose code for radiation protection and radioactive waste management}

FLUKA [6], [7] is a Monte Carlo code simulating the transport and the interactions of particles. Created in 1962, the third main version has been developed and maintained by INFN and CERN. This code has been chosen by the IPN and the iRSD to conduct radiation 
protection studies [8]. The powerful tools developed, like the 3D modelling and visualizing interface FLAIR [9], as the new features like the on-line activation calculation give FLUKA great capabilities to conceive new installations in an optimized way regarding radioprotection, environment and waste management.

\subsection{Benchmarks on ions accelerators}

As developed within the CERN, FLUKA has always been suitable for hadrons accelerators studies, for high energies before and then for lower energies with the successive implementations of the code.

\subsection{Benchmarks on electrons accelerators}

Improvements of low energy neutrons and electrons/photons modules for transport and interactions [10] during the last years are a strong justification to use FLUKA to make radiation protection or activation studies for electron accelerators.

Several plants used FLUKA for radiation protection studies: ARIEL - TRIUMF (Vancouver, Canada) or Spring-8 (Saitama, Japan) [11] for example.

\subsection{Statistical}

In electron accelerators, Bremsstrahlung and photonuclear interactions are predominant. Use of methods of variance reduction for shielding designs is mandatory to optimize the factor of merit (FOM). In the case of ThomX, importance biasing was applied to photonuclear interactions and inelastic interactions with electrons, and the mean free path in materials has been reduced to increase the probability of interactions with photons and electrons. The same techniques were used for Andromede as well as multiplicity biasing (based on importance biasing) for beam particles (proton or alpha).

\subsection{Defining the sources}

Both accelerators have different final scientific purposes, so their operational modes are not related. Sources must be defined considering these specificities.

Andromede will use ion beams to study interactions with targets. Therefore, a two-step method based on the assessment of the production rate for neutrons/photons and X-rays is used.

ThomX will produce X-rays in a storage ring on topup mode. Several leak points for the primary beam are identified all along the accelerator.

\subsubsection{Andromede}

Two kinds of particles productions need to be taking account: X-rays losses within the accelerator tank and the neutrons and gammas produced in Faraday cups.

While conditioning, some X-rays can be emitted through the last titanium electrode tube within the accelerator tank. The model is considered conservative enough: $200 \mathrm{keV}$ electron produced along the electrode within the accelerator's tank at $1 \%$ of maximum intensity $(200 \mu \mathrm{A})$.

For ion beams, neutron and gammas produced in Faraday cups have been assessed using a two-step method with FLUKA:

- First, use of a reduced geometry in order to define neutron $(\mathrm{n})$ and photon $(\mathrm{g})$ yields from 4 $\mathrm{MeV} \mathrm{p}^{+}$and $8 \mathrm{MeV} \mathrm{He}^{2+}$ reactions on natural $\mathrm{C}$. Results are shown in table 1.

Table 1 Neutron and photon yields from $\mathrm{p}+$ and $4 \mathrm{He} 2+$ beams on natural carbon

\begin{tabular}{|c|c|c|c|c|}
\hline $\begin{array}{c}\text { Projectile } \\
/ \mathrm{E}(\mathrm{MeV}) \\
/ \mathrm{I}(\mu \mathrm{A})\end{array}$ & Target & $\begin{array}{c}\text { Secondary } \\
\text { radiation / } \\
\mathrm{E}(\mathrm{MeV})^{1}\end{array}$ & $\begin{array}{c}\text { Production } \\
\text { Yield }\end{array}$ & $\begin{array}{c}\text { References } \\
{[12][13]}\end{array}$ \\
\hline \multirow{2}{*}{$\begin{array}{c}\mathrm{p}^{+} / 4 / \\
10\end{array}$} & \multirow{2}{*}{$\begin{array}{c}\text { Natural } \\
\text { carbon }\end{array}$} & $\mathrm{n} / 0,8$ & $\begin{array}{c}6^{*} 10^{-6} \\
\mathrm{n} / \mathrm{p}\end{array}$ & $\begin{array}{c}\sim 10^{-6} \\
\mathrm{n} / \mathrm{p}\end{array}$ \\
\cline { 3 - 5 } & & $\mathrm{g} / 3,1$ & $\begin{array}{c}5^{*} 10^{-7} \\
\mathrm{~g} / \mathrm{p}\end{array}$ & - \\
\hline \multirow{2}{*}{$\begin{array}{c}{ }_{4} \mathrm{He}^{2+} \\
(\mathrm{a}) / 8 / \\
2,5\end{array}$} & \multirow{2}{*}{$\begin{array}{c}\text { Natural } \\
\text { carbon }\end{array}$} & $\begin{array}{c}\mathrm{n} / 1,5 \\
\mathrm{and} 6,5\end{array}$ & $\begin{array}{c}2^{*} 10^{-5} \\
\mathrm{n} / \mathrm{a}\end{array}$ & $\begin{array}{c}\sim 8^{*} 10^{-6} \\
\mathrm{n} / \mathrm{a}\end{array}$ \\
\cline { 3 - 5 } & & $\mathrm{g} / 4,5$ & $\begin{array}{c}2^{*} 10^{-3} \\
\mathrm{~g} / \mathrm{a}\end{array}$ & - \\
\hline
\end{tabular}

(1): the given energy value is the most probable one in a radiation safety approach.

- The second one in another FLUKA calculation with the whole geometry and those yields as entry data to define the different local shielding thickness.

\subsubsection{ThomX}

ThomX is a standard storage ring using electron as the primary beam. Several feedbacks from exploitation of synchrotron electron rings can be used to localize and define leak points along the machine.

For example, the main leak point in storage rings, like SPEAR3 (Stanford - USA) [14], DELTA (Dortmund Germany) [15] [16], SOLEIL (Saclay - France) [17] or ESRF (Grenoble - France) [18] identified the "septum", component used to inject electron beam into the ring, as the main leak point.

A scraper will be used in the transfer line to improve the quality of the primary beam. It removes electrons located outside the maximum diameter allowed. As a "target with a hole", continuous losses will occur at this point.

Two beam-dumps will be used. The one situated at the end of the LINAC will totally stop the beam in setting mode. Another one will be located at the end of the ring to stop the extracted beam, when X-rays will be produced (Top-up mode). The design of these components are the same as those used at SOLEIL Synchrotron.

With the cooperation of the team in charge of the beam dynamics, five losses points (Fig. 5) have been defined, as presented in table 2 . 


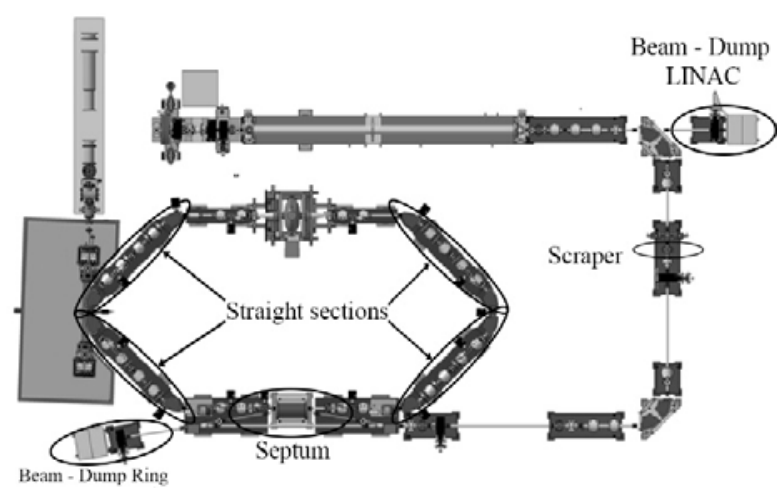

Fig. 5. Losses points localized all along the ThomX machine.

Losses in the scraper have been modelled in this way: the primary beam is directed in the jaws of the scraper. But width of the jaws (copper) are not sufficient to stop the primary beam. In order to stop the propagation of the electrons from the primary beam, a little area situated downstream stops all the electrons leaving the jaws (Fig. 6).

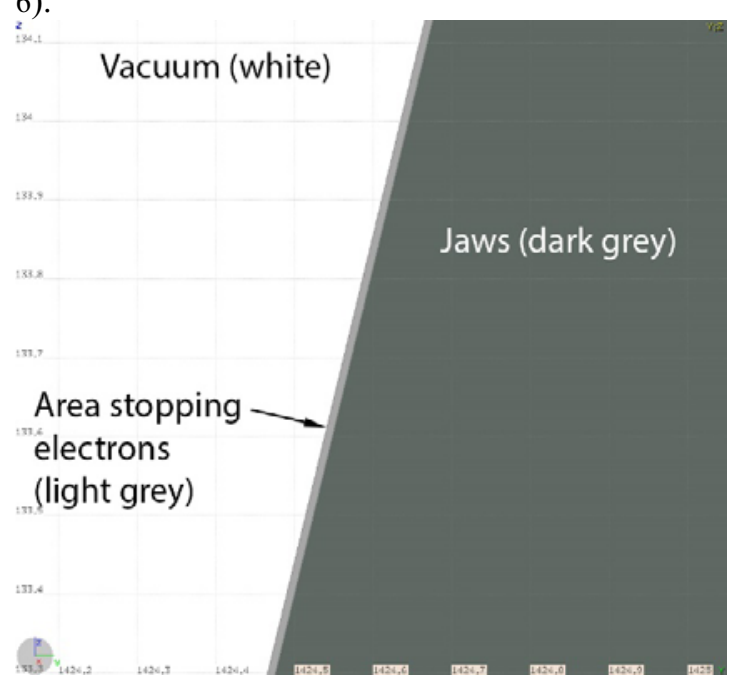

Fig. 6. Modelling scraper losses area. Downstream the jaws (dark grey), an area (light grey) stopped all leaving electrons.

Losses in the straight sections came from electrons situated at the periphery of the bunch [19] [20]. They are modelled as a cylinder starting at the center and propagating along the beam pipe (Fig. 7.)

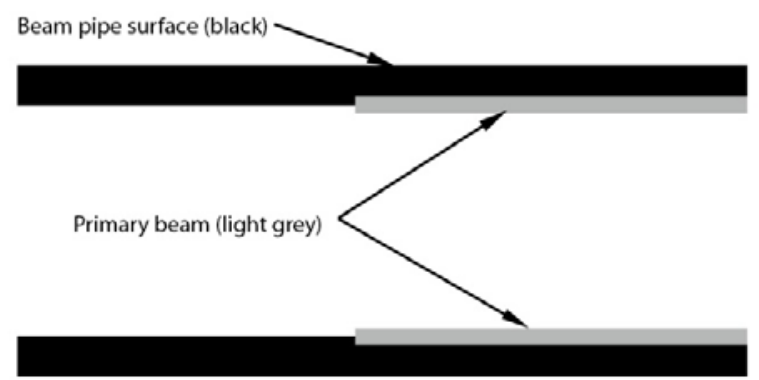

Fig. 7. Modelling straight section losses (side view). The primary beam (light grey) is a cylinder which diameter is slightly larger than the beam-pipe (black).
Table 2. Losses points defined all along ThomX

\begin{tabular}{|c|c|c|}
\hline Localization & $\begin{array}{c}\text { Percentage of } \\
\text { loss }(\%)\end{array}$ & $\begin{array}{c}\text { Current load of } \\
\text { the primary } \\
\text { beam (nC) }\end{array}$ \\
\hline $\begin{array}{c}\text { Beam - dump } \\
\text { LINAC }\end{array}$ & 100 & 1,5 \\
\hline $\begin{array}{c}\text { Beam - dump } \\
\text { ring }\end{array}$ & 100 & 0,9 \\
\hline $\begin{array}{c}\text { Septum - } \\
\text { loading }\end{array}$ & 10 & 1 \\
\hline $\begin{array}{c}\text { Septum - } \\
\text { emptying }\end{array}$ & 10 & 1 \\
\hline $\begin{array}{c}\text { Straight sections } \\
\text { of the ring }\end{array}$ & 4 & 1,5 \\
\hline Scraper & 15 & \\
\hline
\end{tabular}

\subsection{Geometrical modelling}

\subsubsection{Andromede}

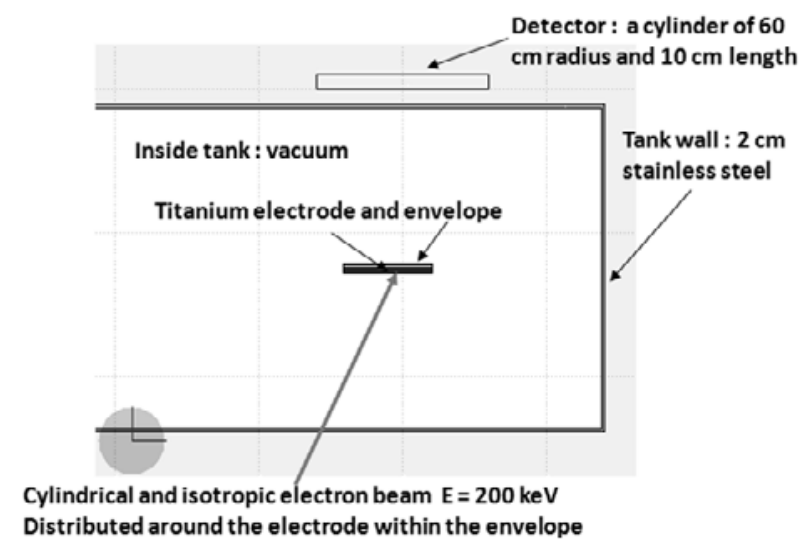

Fig. 8. Modelling X-rays losses along the last titanium electrode tube within the stainless steel accelerator tank.

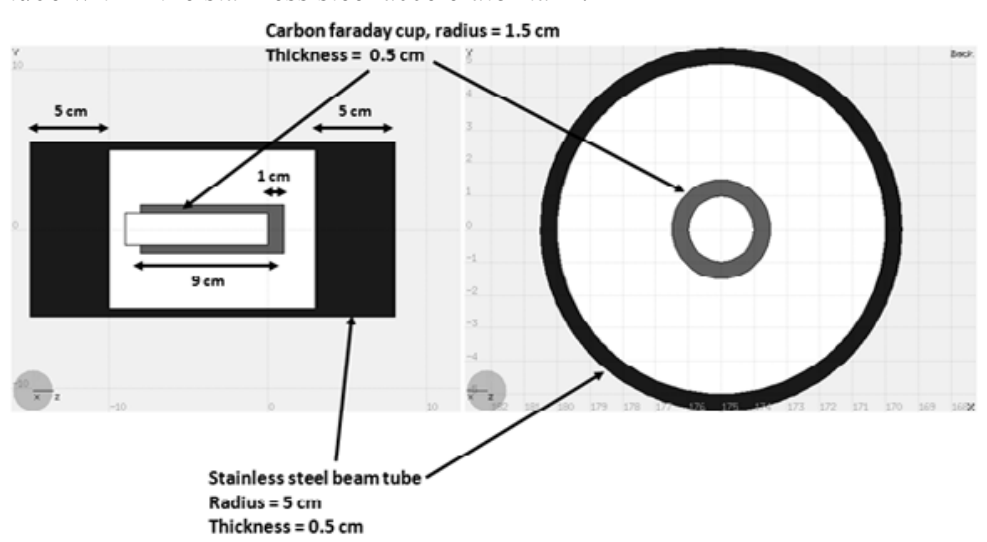

Fig. 9. Modelling carbon Faraday cup within stainless steel beam tube 


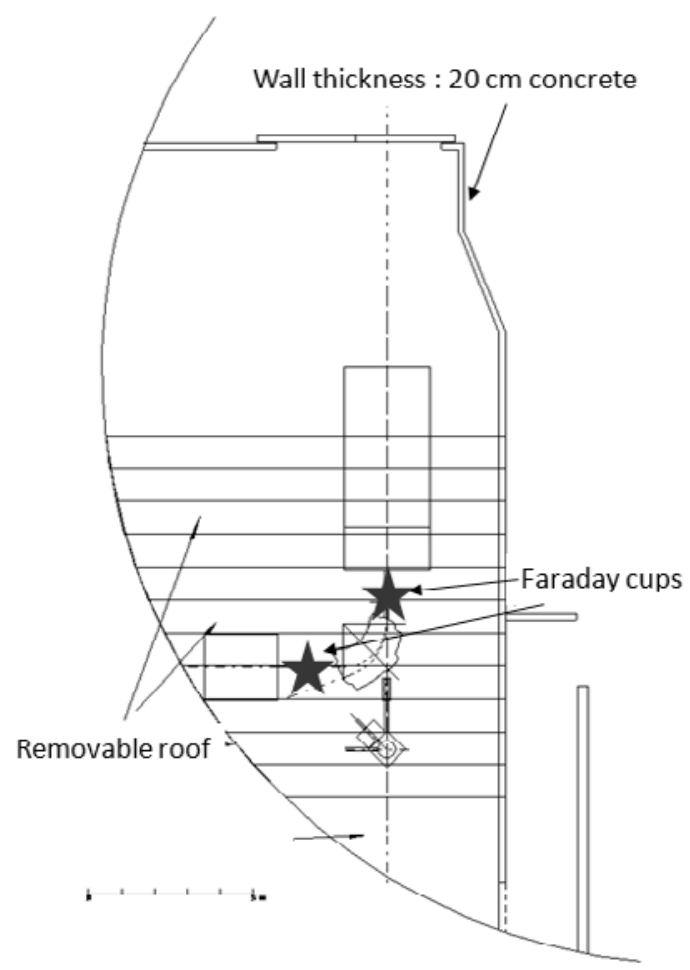

Fig. 10. Modelling the whole geometrical situation. The two stars show the location of the two Faraday cups as beam dump.

\subsubsection{ThomX}

At first, ThomX was intended to be the sole device in the "Igloo" building. First batch of numerical simulations was made to confirm the efficiency of the walls of the building (Fig. 11).

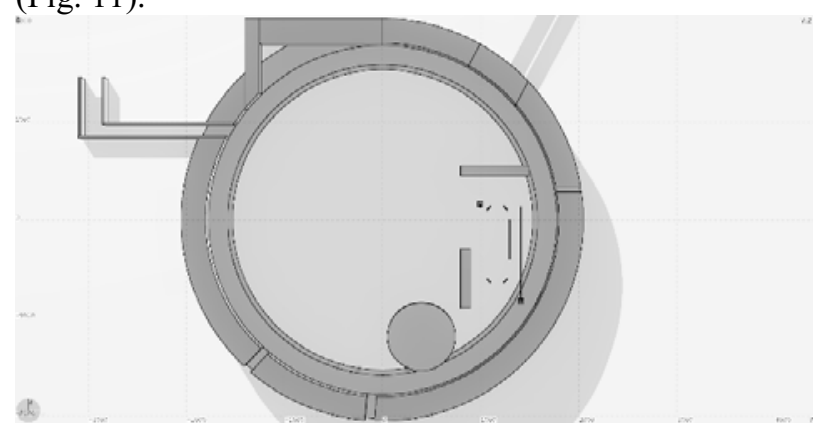

Fig. 11. First version of the geometrical modelling containing only the walls of the Igloo Building. Accesses and basements are missing.

When Andromede and ThomX merged in the IGLEX project, numerical simulations were used to design the hutches. The first step consisted in defining the minimum thickness of the hutch walls considering the radiation safety objectives and specific constraints (technical and financial). After that, a first design of the hutch was provided by the ThomX project team.

Therefore, new batches of numerical simulations have been done in an iterative way (Fig. 12). Each nonconformity with the safety and technical objectives was corrected by creating local shielding to reduce radiation leaks at the source of production or by modifying the design of the hutch or the materials used for the walls for example.

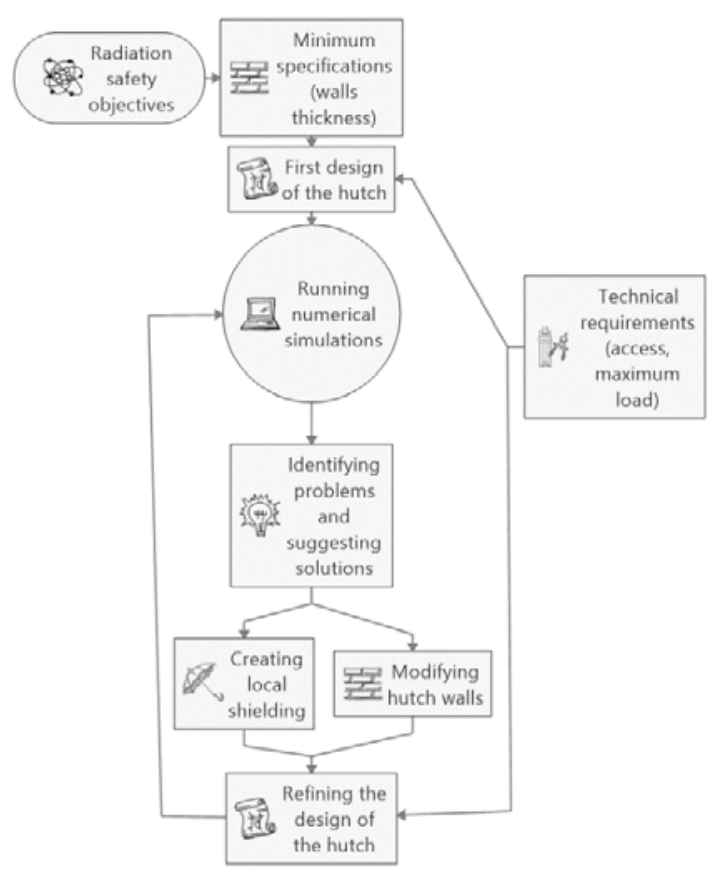

Fig. 12. Geometrical modelling process during the conception phase for ThomX.

The great flexibility of this process complied with the continuous conception of the ThomX machine: modifications of the machine, adapted integration in the hutch. The counterpart was the large amount of time needed to run each batch of numerical simulations (changing geometries, debugging, setting up the physics, running time, data analysis).

Concerning the machine, only parts involved in beam losses have been modelled (Fig. 12). Dipoles yokes of the ring have been included because they could alter the secondary radiations. Septum was modelled following indications provided by the "pulsed devices" team.

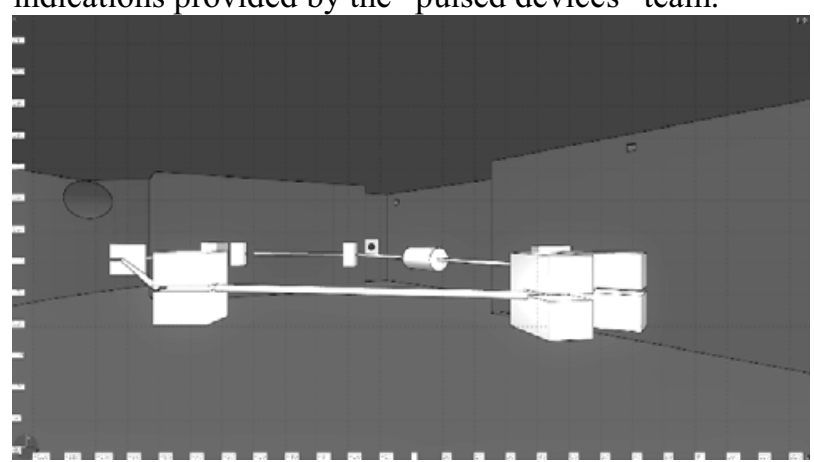

Fig. 13 3D modelling of the accelerator used in FLUKA. 


\section{Andromede shielding design}

\subsection{Description}

Most of the time this accelerator facility will not produce radiation at all as the studied physics will only lead to subCoulomb reactions. But in case of light ions beams (proton or alphas), there will be some rare nuclear reactions while interacting with light material like carbon (typical Faraday cups). Identified radiation points are Bremsstrahlung X-rays from tank while conditioning beam, gamma rays and neutrons produced in nuclear reaction in the vacuum chamber or the Faraday cups while the light ion beam is stopped.

To keep produced radiation in that particular perimeter the approach is two-folded approach:

- A global shielding made of concrete (20 cm thick) and a half roof (45 cm thick) for the Andromede hutch.

- Two local shielding around the point of interaction (the Faraday cups or beam dumps) with classic shielding materials (high density polyethylene (PE) for neutrons and lead or stainless steel for photons).
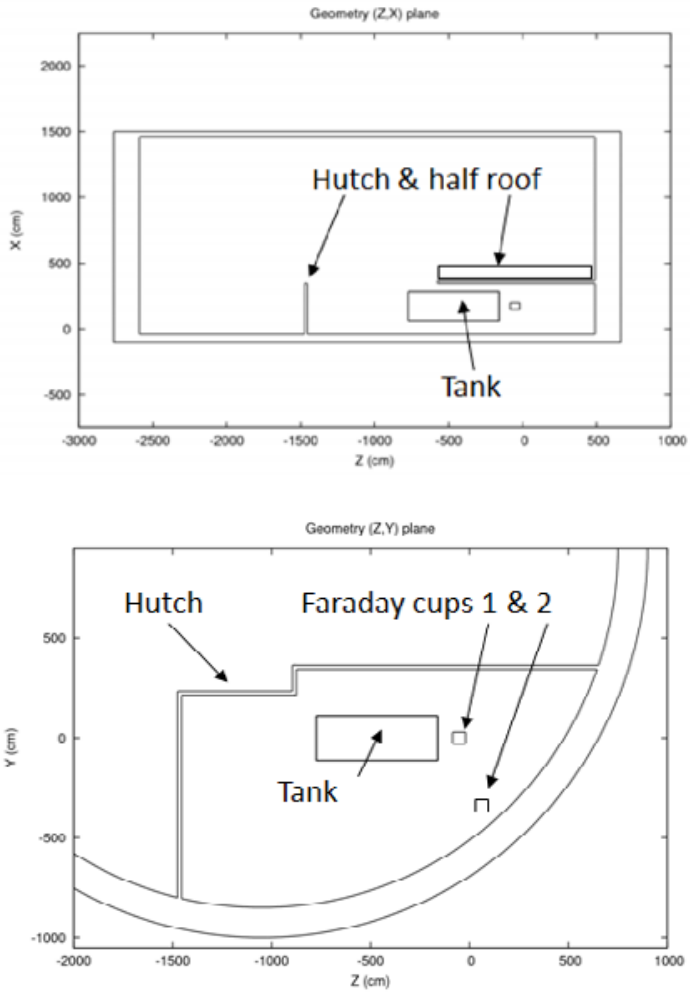

Fig. 14 Display of Andromede situation, vertical (left) and horizontal (right) cuts.

\subsection{X-ray radiation from the tank}

The plots show that in this case the shielding is sufficient to insure an exposure under the limits outside the hutch.
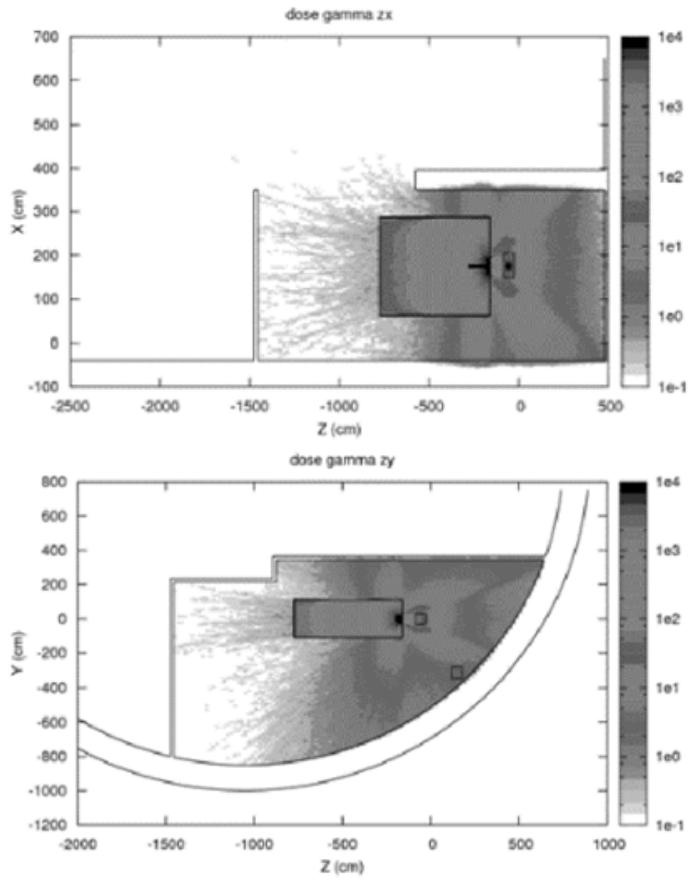

Fig. 15 Display of ambient dose rate in $\mu S v \cdot h^{-1}$ for X-ray production within the tank, vertical (left) and horizontal (right) cuts.

\subsection{Faraday cups}

For alphas: $5 \mathrm{~cm}$ PE \& $10 \mathrm{~cm}$ lead, gamma dose showed in the case of Faraday cup $n^{\circ} 1$.
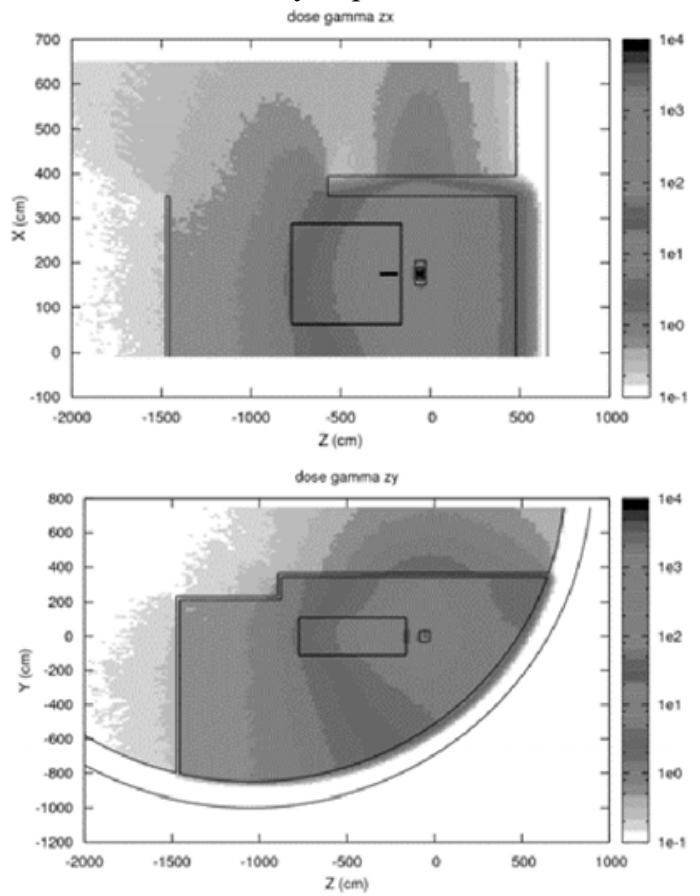

Fig. 16 Display of ambient dose rate in $\mu S v \cdot h^{-1}$ for an $8 \mathrm{MeV} /$ 2,5 $\mu \mathrm{A}^{4} \mathrm{He}^{2+}$ beam interacting in Faraday cup n ${ }^{\circ} 1$, vertical (left) and horizontal (right) cuts (gamma dose). 
For protons: $15 \mathrm{~cm} \mathrm{PE}$, neutron dose showed in the case of Faraday cup $n^{\circ} 2$.
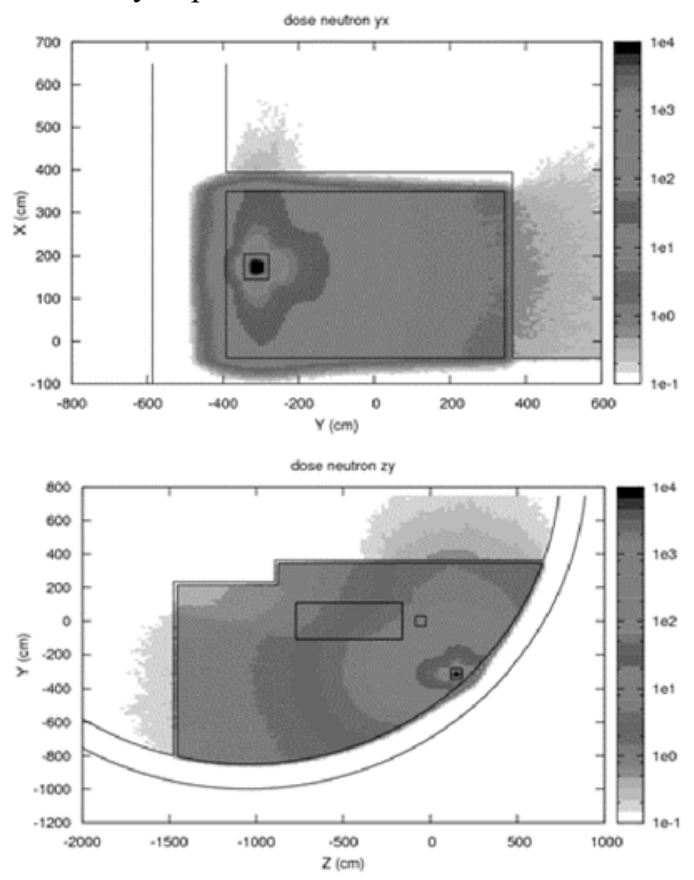

Fig. 17 Display of ambient dose rate in $\mu \mathrm{Sv} \cdot \mathrm{h}^{-1}$ for a $4 \mathrm{MeV} / 10$ $\mu \mathrm{A} \mathrm{p}^{+}$beam interacting in Faraday cup ${ }^{\circ} 2$, vertical (left) and horizontal (right) cuts (neutron dose).

\section{Thom $X$ design shielding}

\subsection{Accelerator Hutch}

The main objective is to classify radiologically the circulation area as a monitored area. At first approximation, using analytical solutions, the minimum thickness for the walls of the hutch needs to be equal to $150 \mathrm{~cm}$ of ordinary concrete for high-dispersion straight sections losses. Some beam-loss locations produce higher level of radiation and need thicker walls. The floor load and budget for the infrastructure being limited, thickness of some walls needs to be optimized.

In a first time, the minimum thickness of the roof of the accelerator hutch was proportioned to ensure an ambiant dose rate $\dot{H}^{*}(10)$ inferior to $7.5 \mu \mathrm{Sv} \cdot \mathrm{h}^{-1}$, limit value to define a monitored area. One meter of ordinary concrete was required. It had to be reduced because of technical issues, as the total weight or the supporting. Therefore, the project team, in accordance with the radiation safety team, decided to forbid the access to the upper part of the hutch during the operation of ThomX accelerator. After, a step-by-step method was used with numerical simulations to optimize the thickness of the roof, removing $10 \mathrm{~cm}$ of ordinary concrete by iteration. Considering the height between the roof of the hutch and the one of the Igloo building (more than 2 meters), the skyshine effect is negligible. Finally, the thickness of the roof will be $55 \mathrm{~cm}$ without altering the radiation zoning on the common area below the top of the roof.

Mazes were designed for the North and the South accesses of the hutch. Thickness of the South walls has been reduced and some parts removed to decrease the floor load. A prohibited area must be created outside the hutch to forbid presence of people during the work of the accelerator (Fig. 18).

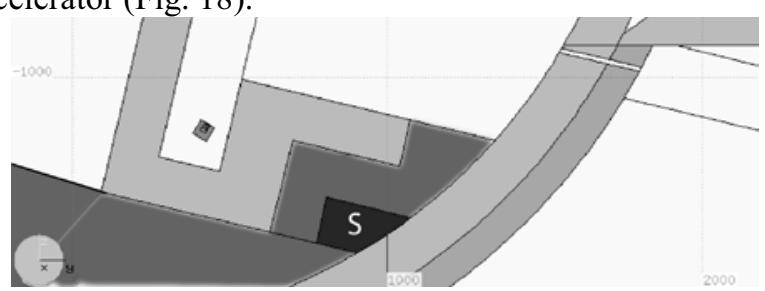

Fig. 18 South access of the accelerator hutch. The black wall (with an "S") has been removed in the final design. A prohibited area (middle gray) is created when the accelerator runs.

In the North maze, the thickness of one of the wall has to be proportioned according to the width needed to pass through the corridor leading to the control room toward the circulation area. Considering the first specifications for shielding, 1.5 meter of ordinary concrete was needed so the width available is around $30 \mathrm{~cm}$ (Fig. 19). Then, the thickness of the wall has been reduced using barite concrete $(\mathrm{d}=3.2)$. In addition, a local shielding has been designed for the beam-dump of the LINAC (see 4.2).

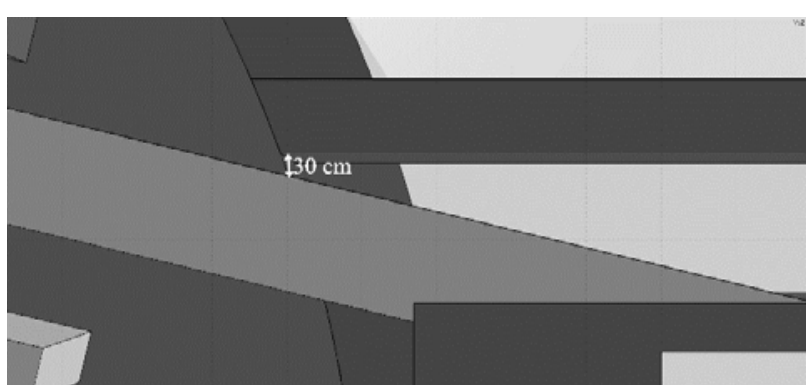

Fig. 19 Width between the wall of the North maze (gray) and the corridor between Igloo and control room (black) with ordinary concrete and 1.5 meter of thickness.

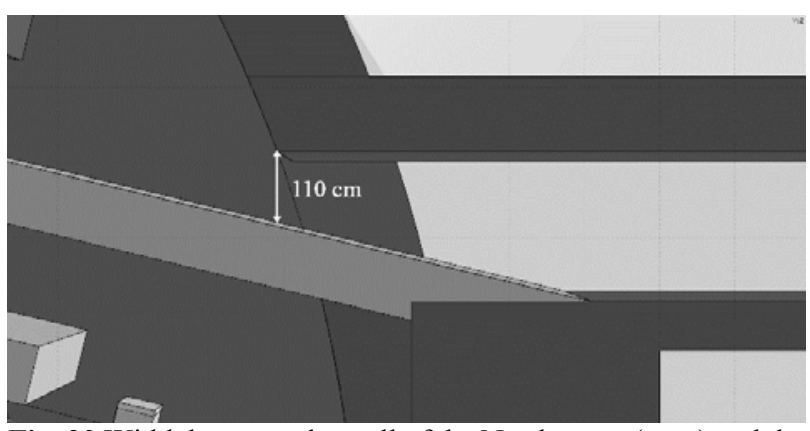

Fig. 20 Width between the wall of the North maze (gray) and the corridor between Igloo and control room (black) with barite concrete and $80 \mathrm{~cm}$ of thickness.

Other improvements have been made to increase the efficiency of the shielding: the different holes needed have been positioned to reduce risks of radiation leaks (heights, angles, slope) and local shielding have been designed. The final version of the accelerator hutch (Fig. $21)$ is currently under construction until the end of September 2016 (Fig. 22). 


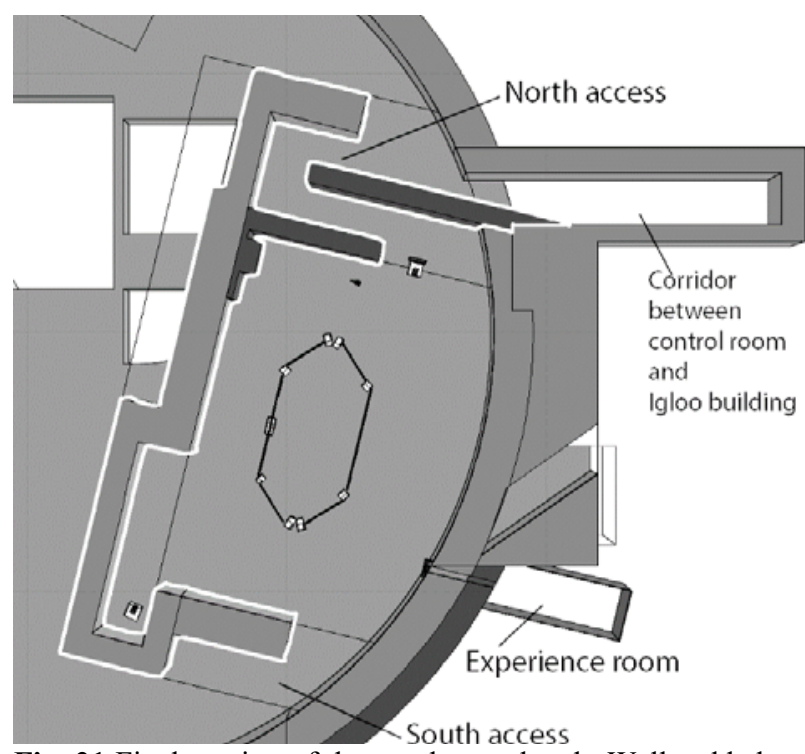

Fig. 21 Final version of the accelerator hutch. Walls added are outlined in white.

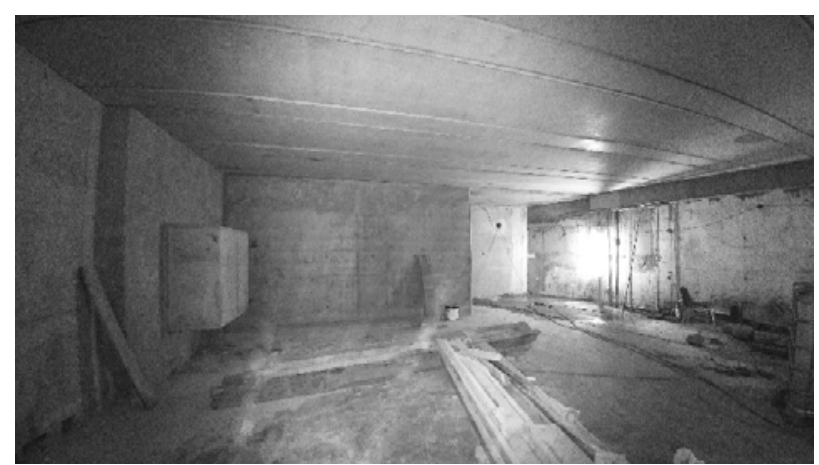

Fig. 22 View from the North maze of the accelerator hutch under construction (July 2016).

\subsection{Local shielding}

As seen in 4.1, the width of the accelerator hutch walls has been optimized using local shielding on critical elements as the scraper for example. Local shielding is needed too for the use of X-rays, produced. So, a beamshutter for the X-ray line has been designed.

The scraper is the main beam-loss point, excepted beam-dumps. To comply with the radiation protection objective, a local concrete shielding has been designed on a wall of the accelerator hutch. Using of barite concrete and a two-part shield optimized the volume of concrete used (Fig. 23).

Another shielding has been designed too, to reduce exposure to radiations when the accelerator is off. Jaws in copper will be highly activated after the shutdown. So, the system will be placed in a lead and tungsten box (Fig. 24). The tungsten increases the efficiency of the shielding and protects the lead from activation.

As explain in 2.6.2, many changes were made during the conception phase and in particular, the diameter of the beam-line was increased. So a lead and tungsten pipe has been added to surround the vacuum pipe located at the front of the scraper. It will collimate the secondary particles produced when accelerator is on.

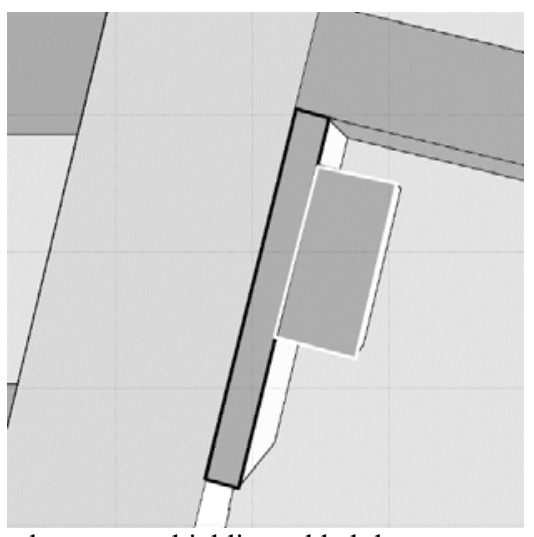

Fig. 23 Local concrete shielding added downstream the scraper (perpendicular). In black line, the first part $(300 * 25 * 277 \mathrm{~cm})$. In white line, the second one $(130 * 60 * 130 \mathrm{~cm})$.

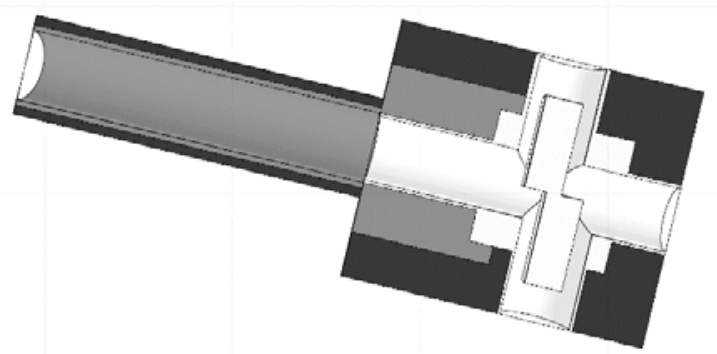

Fig. 24 Top view of the shielding of the scraper. The tungsten parts are in dark grey, the lead ones in black. The pipe shield is located downstream the scraper to collimate secondary particles produced when accelerator is on.

A hole is needed to transport X-rays through the Igloo wall toward the experience room, situated in the contiguous building. The opening is situated in the beam plan, at about $5.5 \mathrm{~m}$ from the interaction point. Two issues needed to be resolved: development of applications depends on the energy spectrum of the X-rays, itself depending on the opening angle of the beam created (Fig. 25). Furthermore, the diameter of the hole needs to be enough to exploit the largest spectra of X-rays.

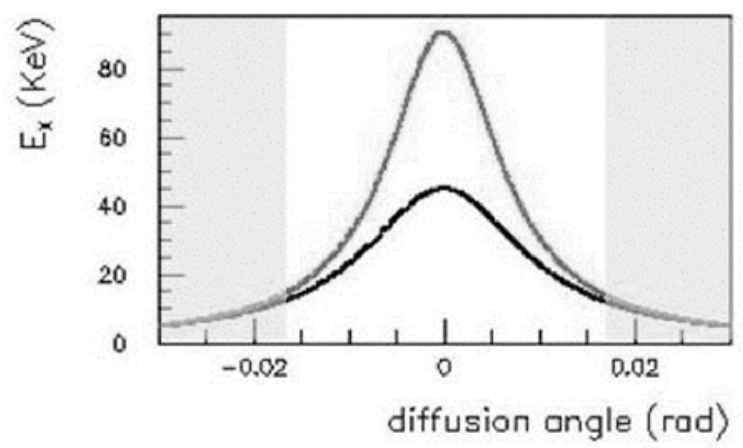

Fig. 25 Simulation of the energy of the X-rays produced by Compton backscattering effect versus diffusion angle. The weakest energy is produced in the largest diffusion angle [2].

Nevertheless, users need to work in the experience room without stopping the accelerator (setting up the beam-line, changing samples...) and without being 
exposed to radiation. A balance between radiation protection and scientific performances has been made designing a beam-shutter coupled with a shielding inside the accelerator hutch (Fig. 26): the beam-shutter have been designed to stop X-rays and to reduce the scattered radiation coming from the accelerator. The lead shielding, situated inside the accelerator hutch, surrounds the beamshutter and the pipe transporting the X-rays through the walls. We can see in fig. 26 that the hole in the wall has a larger diameter $(25 \mathrm{~cm})$ than the hole in the shielding $(20$ $\mathrm{cm})$. The smallest one is sufficient for scientific exploitation, but if radiation leaks are weaker than anticipated, a new shielding will be designed to use a wider X-rays energy spectrum.

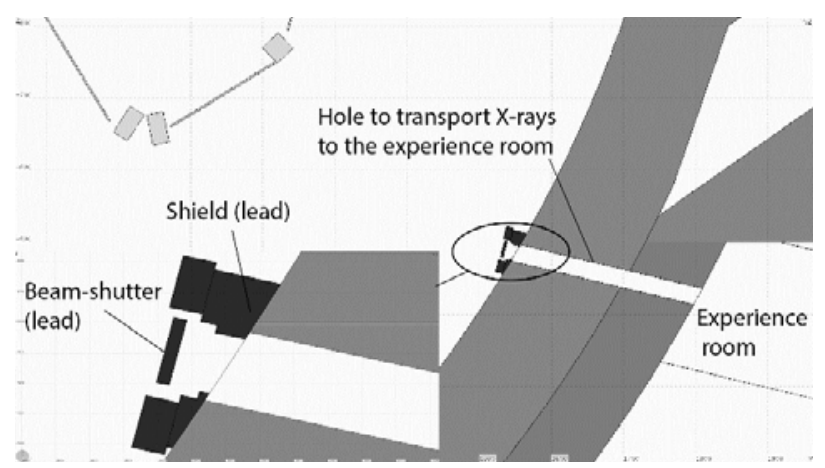

Fig. 26 Beam-shutter and shielding associated in the X-rays transport line.

\subsection{Results}

Balance between radiation protection, technical and financial optimization is obtained using full capacities from FLUKA. Use of Monte-Carlo code allows many improvements in shielding design by identifying and refining critical areas.

For ThomX accelerator hutch, additional local shielding has been designed to reduce thickness of concrete walls, in particular for the roof and the mazes (Table 3). Weight gains were important as were costsavings: more than 250 tons of concrete corresponding to more than $100 \mathrm{k} €$ were saved.

The shielding complies with the radiation protection objectives, where the ambient dose rate needs to be lower than $3 \mu \mathrm{Sv}^{-1} \mathrm{~h}^{-1}$ in the common area opened when the machines will work (Fig. 27). However, some places will be closed to forbid the presence of workers during the operation of ThomX: the roof of the hutch and the south of the Igloo building.

The South access of the hutch will be delimited by a fence. A safety door interlocked with the safety system will control the access: possible when ThomX is off, prohibited when it is on.

A fixed ladder with safety cage, located in the South access, will be used to climb on the roof of the accelerator hutch. Safety barriers will be placed all along the roof to prevent falls or climbing up. The use of the travelling crane will be prohibited when one accelerator is working.
Table 3 Reductions of the thickness of concrete walls applied on the accelerator hutch. Weight of concrete removed and money saved have been assessed. Costs for local shielding designed and concrete added for the scraper are estimated too.

\begin{tabular}{|c|c|c|c|}
\hline Zones & $\begin{array}{l}\text { Reduction of } \\
\text { the thickness } \\
\text { of concrete } \\
\text { walls }\end{array}$ & $\begin{array}{l}\text { Weight } \\
\text { removed }(\mathrm{t})\end{array}$ & $\begin{array}{c}\text { Money } \\
\text { saved }(\mathrm{k} €)\end{array}$ \\
\hline Roof & $\begin{array}{l}\text { Thickness } \\
\text { reduced by } \\
50 \mathrm{~cm}\end{array}$ & 248 & 108 \\
\hline $\begin{array}{l}\text { North } \\
\text { maze }\end{array}$ & $\begin{array}{l}\text { Thickness of } \\
\text { some walls } \\
\text { reduced by } \\
50 \mathrm{~cm} \\
\text { (normal } \\
\text { concrete) } / 80 \\
\text { cm (barite } \\
\text { concrete) }\end{array}$ & 33 & 14 \\
\hline $\begin{array}{l}\text { South } \\
\text { maze }\end{array}$ & $\begin{array}{l}\text { One wall } \\
\text { removed and } \\
\text { thickness } \\
\text { reduced by } \\
50 \mathrm{~cm}\end{array}$ & 69 & 30 \\
\hline \multicolumn{2}{|c|}{ Total } & 350 & 152 \\
\hline \multicolumn{3}{|c|}{$\begin{array}{l}\text { Estimated cost for local shielding } \\
\text { (LINAC beam-dump, scraper, beam- } \\
\text { shutter for the X-rays line) }\end{array}$} & $20-30$ \\
\hline \multicolumn{3}{|c|}{$\begin{array}{l}\text { Cost for barite concrete added for } \\
\text { scraper }\end{array}$} & 66 \\
\hline
\end{tabular}

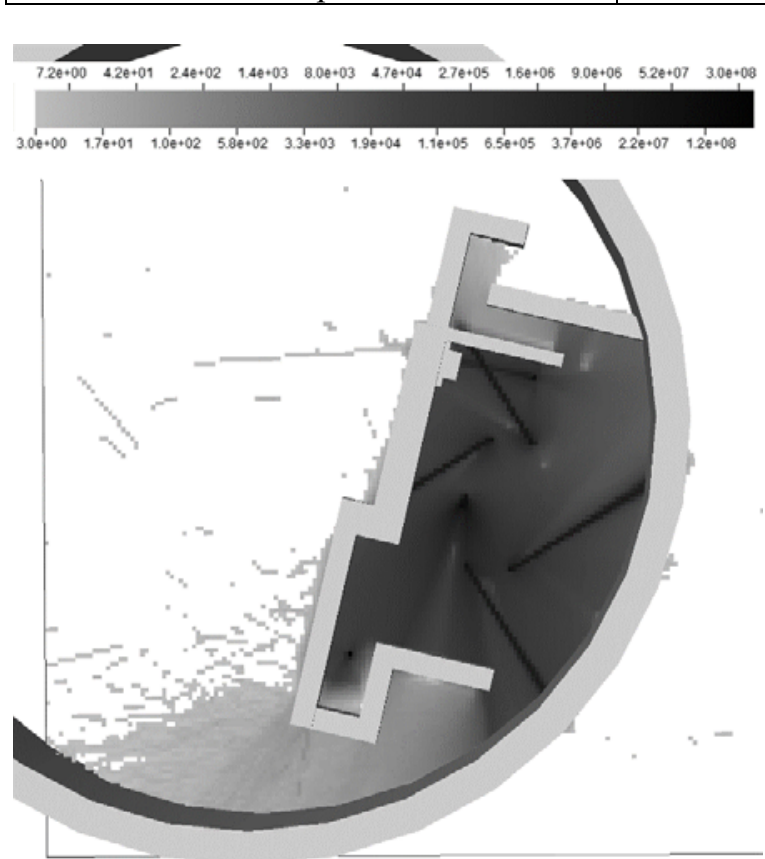

Fig. 27 Ambient dose rate during the exploitation of Thom $X$ in the hutch. The lower limit is $3 \mu \mathrm{Sv} \cdot \mathrm{h}^{-1}$. In the south of the hutch, access will be prohibited (made with SimpleGeo [21]).

\section{Conclusion}

Those simulations were determining to define the nature and dimensions of the shielding design (local and global ones) as well as to demonstrate the compliance with respect of public and worker regulations in order to plan 
the building of the infrastructures. In particular, those studies are valuable assets to obtain the authorization to exploit those facilities from the French nuclear authority.

The two project teams are collaborating to define a common safety and radiation protection supervision, taking into account various interactions (accesses, radiation supervision system, etc.) to comply with the NF M 62-105 [5] French standard for industrial accelerators.

As explain above (see 1), each accelerator will be operated by different laboratory (Andromede-IPN; ThomX-LAL). Thus, occupational health \& safety and radiation protection needs a specific organization, taking account of the interaction between the exploitation of the two plants. Each safety radiation team from the LAL and the IPN will intervene for it accelerator. iRSD team will probably collaborate with the two laboratories for the coordination and the management of the radiation protection.

\section{Acknowledgment}

This work is supported by the French "Agence Nationale de la Recherche" as part of the program "Investing in the Future" under reference ANR-10-EQPX-51. This work was also supported by grants from Région Ile-de-France.

\section{References}

[1] M. J. Eller, E. Cottereau, V. Verkhoturov, A. Delobbe, J. Renaud, E. A. Schweikert and S. DellaNegra, Andromede Project : Surface analysis and nano-particle surface interactions in the keV to Mev Energy Range, Leuven, 2014.

[2] A. Variola, J. Haissinski, A. Loulergue and F. Zomer, "ThomX : Technical design report," LAL, Orsay, 2013.

[3] N. Pauwels, J.-M. Horodynski, P. Robert and A. Tadjeddine, "Démantèlement de l'installation nucléaire de base 106 (LURE)," Radioprotection, vol. 48, no. 4, pp. 545-561, October 2013.

[4] J. Bonis, R. Chiche, R. Cizeron, M. Cohen, E. Cormier, P. Cornebise, N. Delerue, R. Flaminio, D. Jehanno, F. Labaye, M. Lacroix, R. Marie, B. Mercier, C. Michel, Y. Peinaud, L. Pinard, C. Prevost, V. Soskov, A. Variola and F. Zommer, "Non-planar four-mirror optical cavity for high intensity gamma ray flux production by pulsed laser beam Compton scattering off GeV-electrons," Journal of instrumentation, January 2012.

[5] AFNOR, "Energie nucléaire - Accélérateurs Industriels : Installations," AFNOR, La Plaine Saint-Denis, 1998.

[6] T. T. Bölhen, F. Cerutti, M. P. Chin, A. Fasso, A. Ferrari, P. G. Ortega, A. Mairani, P. R. Sala, G. Smirnov and V. Vlachoudis, "The FLUKA Code: Developments and Challenges for High Energy and Medical Applications," Nuclear Data Sheets, vol. 120, pp. 211-214, June 2014.
[7] A. Ferrari, P. R. Sala, A. Fasso and J. Ranft, "FLUKA : a multi-particle transport code," CERN, Geneva, 2011.

[8] CNRS-IN2P3-IPNO, "IPN Orsay - Radioprotection Dosimétrie: SPR," IPN Orsay, [Online]. Available: http://ipnwww.in2p3.fr/Radioprotectiondosimetrie-SPR. [Accessed January 2016].

[9] V. Vlachoudis, "FLAIR : a powerful but user friendly graphical interface for FLUKA," in Proceedings of international conference on mathematics, computationnal methods and reactor physics, Saratoga Springs, 2009.

[10] A. Fasso, P. R. Sala and A. Ferrari, "Designing electron accelerator shielding with FLUKA," in $8 t h$ Int. Conf. on Radiation Shielding, Arlington (Texas), 1994

[11] Y. Asano, "Shielding design for the electron transport line of XFEL facility, SACLA to SPring8 storage ring," in 7th International workshop on radiation safety at Synchrotron Radiation Sources, Brookhaven, 2013.

[12] National Council on radiation Protection and Measurements, "Radiation Protection for Particle Accelerator Facilities : Recommendations of the National Council on Radiation Protection and Measurements," NCRPM, Bethesda, Md, 2003.

[13] T. D. Cradduck, "NCRP REPORT NO. 51: Radiation Protection Design Guidelines for 0,1-100 $\mathrm{MeV}$ Particle Accelerators Facilities," Journal of Nuclear Medecine Technology, vol. 6, no. 1, p. 40, March 1978.

[14] S. H. Rokni and J. C. Liu, Radiation safety considerations for design of the SPEAR3 storage ring, Stanford: SLAC, 2003.

[15] G. Schmidt, E. Kasel, K. Wille, M. Körfer, H. Henschel and J. Kuhnhenn, "Optical fibre beam loss monitors for storage rings at DELTA," in Proceedings of EPAC 2002, Paris, 2002.

[16] G. Schmidt, Status of the DELTA machine operation ESLS 200, Dortmund: Universität Dortmund, 2003.

[17] M.-A. Tordeux, P. Lebasque, P. Gros, J. Da Silva and P. Feret, "General performances of the injection scheme into the SOLEIL storage ring," in Proceedings of EPAC 2004, Lucerne, 2004.

[18] P. Berkvens and P. Colomp, Measurements of radiation levels inside the ESRF storage ring, Grenoble: ESRF.

[19] H. Lengeler, Radiation protection of measuring setups for LEP 4-cell cavity, Geneva: CERN, 1989.

[20] H. Lengeler, X-ray radiation from a module of 4 superconducting cavities, Geneva: CERN, 1989.

[21] C. Theis, K. H. Buchegger, M. Brugger, D. ForkelWirth, S. Roesler and H. Vincke, "Interactive three dimensional visualization and creation of geometries for Monte Carlo simulations," Nuclear instruments and methods in physics research, vol. 562, pp. 827-829, 2006. 